\title{
O CONCEITO DE TECNOLOGIA NA CONCEPÇÃO DE ÁLVARO VIEIRA PINTO: CONTRIBUIÇÕES PARA A EDUCAÇÃO A DISTÂNCIA
}

\author{
Camila Tecla Mortean Mendonça ${ }^{1}$, Patrícia L. L. Mertzig Gonçalves de Oliveira ${ }^{2}$, Maria Luisa Furlan \\ Costa $^{3}$ \\ ${ }^{1}$ Centro Universitário de Maringá - UNICESUMAR, Curso de Pedagogia a distância, Maringá, PR. ${ }^{2}$ Universidade do \\ Oeste Paulista - UNOESTE, Faculdade de Artes, Ciências, Letras e Educação de Presidente Prudente, Presidente \\ Prudente, SP. ${ }^{3}$ Universidade Estadual de Maringá - UEM, Departamento de Fundamentos da Educação, Maringá, PR. E- \\ mail: teclacamila@hotmail.com
}

\section{RESUMO}

O uso das tecnologias educacionais é assunto recorrente em reflexões acerca da Educação a Distância (EaD). A utilização das Novas Tecnologias da Informação e Comunicação (TIC) tem sido o principal meio para que grande parte de cursos ofertados na modalidade alcancem milhares de pessoas em todo o mundo. Nesse sentido, o presente artigo tem como objetivo expor o conceito de tecnologia discutido por Álvaro Vieira Pinto (2005) e traçar algumas considerações em relação as tecnologias utilizadas na EaD. De característica bibliográfica, o artigo toma como base 0 primeiro volume da obra de Vieira Pinto intitulado "O Conceito de Tecnologia". Na obra, o homem inventa e fabrica ferramentas que lhe são úteis no momento e toda tecnologia deve ser sempre contextualizada historicamente. As tecnologias educacionais são consideradas úteis para a EaD, mas não como essência da modalidade que pode tornar a reflexão e ação pedagógicas reféns da tecnologia disponível.

Palavras-Chave: Conceito de Tecnologia; Álvaro V. Pinto; Educação a Distância; Tecnologias educacionais.

\section{THE CONCEPT OF TECHNOLOGY IN DESIGN ALVARO PINTO VIEIRA: CONTRIBUTIONS FOR DISTANCE EDUCATION}

\begin{abstract}
The use of educational technologies is a recurring subject in reflections on Distance Education (DE). The use of New Information and Communication Technologies (ICT) has been the main way for much of courses offered in the modality to reach thousands of people around the world. In this sense, this article aims to expose the concept of technology discussed by Alvaro Vieira Pinto (2005) and draw some considerations regarding the technologies used in distance education. With bibliographical feature, the article builds on the first volume of the work of Vieira Pinto entitled "Technology Concept". In the work, the man invents and manufactures tools that are useful at the moment and all the technology must always be contextualized historically. Educational technologies are considered useful for distance education, but not as the essence of the game that can make teaching reflection and action hostages of available technology.
\end{abstract}

Keywords: Concept of Technology; Alvaro V. Pinto; Distance Education; Educational technologies. 


\section{INTRODUÇÃO}

A tecnologia sempre acompanhou o desenvolvimento humano. O homem primitivo, em busca de sua sobrevivência, utilizou diferentes artefatos disponíveis no meio, como ferramentas que o auxiliaram em tarefas que ele não seria capaz de realizar somente com o uso das mãos. $A$ tecnologia, enquanto ferramenta que expande a ação do homem no mundo, ao mesmo tempo que o auxilia a ser adaptar melhor ao meio e produzir seu próprio alimento, também contribuiu para o seu desenvolvimento cognitivo.

Nesse sentido, é possível observar diferentes artefatos tecnológicos que foram criados, confeccionados e manipulados pelo homem ao longo da história e nas diferentes culturas humanas. Assim como a produção artística, toda humanidade desenvolveu algum tipo de tecnologia, porém, cada cultura criou seus próprios artefatos a partir de necessidades específicas, dentro da particularidade de seu modo de vida e concepção de mundo.

Observando-se a história da civilização ocidental, cujo percurso inicia-se na Europa, muitos recursos tecnológicos foram criados a partir do conhecimento que fosse suficiente para tal criação e também a necessidade humana da tecnologia. Como exemplo, temos o tipografo criado pelo alemão Gutemberg no século XV, que foi uma tecnologia que permitiu a cópia de livros, jornais, panfletos e outros impressos de forma rápida e mais eficiente que o sistema anterior, de cópias à mão. Isso revolucionou diversos setores além do econômico, pois a informação passou a ser divulgada de forma mais ampla e rápida.

Outras invenções humanas como, por exemplo, a energia elétrica, máquina a vapor, uso da pólvora entre tantas outras que, como se sabe, não só contribuíram para o avanço tecnológico humano, mas também fomentaram as grandes revoluções como a Francesa e a Industrial. Independente do uso que se faz com as tecnologias, estas permite ao homem a adaptar-se a natureza e o auxilia diariamente em suas tarefas.

O homem é um ser destinado a viver necessariamente na natureza. Apenas, o que se entende por "natureza" em cada fase histórica corresponde a uma realidade diferente. Se no início era o mundo espontaneamente constituído, agora que o civilizado consegue cercar-se de produtos fabricados pela arte e pela ciência, serão estes que formarão para ele a nova "natureza" (PINTO, 2005, p. 37).

Atualmente, com o advento da internet e a criação da World Wide Web, a sociedade passou por mais uma mudança significativa quando desenvolve um novo meio de se comunicar e de estabelecer relações sociais. Os recursos comunicacionais também influenciaram a Educação, que, portanto, passa a enfrentar recentes desafios quando apropria-se dessa tecnologia com o objetivo de contribuir com o processo de ensino e de aprendizagem dos alunos. Isso pode ser observado principalmente na Educação a Distância (EaD).

Historicamente, a EaD sempre fez uso de diferentes tecnologias. A já citada invenção da imprensa, por exemplo, pode ser considerada uma tecnologia que tornou possível estudar sem a presença física do professor. Isso porque a impressão e difusão de muitas cópias de um mesmo livro contribuíram de forma singular com a busca pelo conhecimento e informação. Anterior a essa invenção, os livros eram manuscritos, o que os tornava muito caros e pouco acessíveis (ALVES, 2010).

Experiências posteriores envolvendo diferentes tecnologias na $E a D$, como a correspondência, foram registradas na Inglaterra, em 1840; na Alemanha, em 1856; nos Estados Unidos, em 1874; e na Suécia, em 1883 (ALVES, 2010). Segundo o mesmo autor, a grande expansão da EaD se deu, principalmente, na França, Inglaterra e Espanha, nas quais podemos destacar o Centre National de Enseignement a Distance e a Universidad National de Educación a Distance. 
No Brasil, o marco histórico da EaD, de acordo com Alves (2010), foi a fundação da Rádio Sociedade do Rio de Janeiro, em 1923, por um grupo liderado por Henrique Morize e Edgar Roquette-Pinto, com o objetivo de levar a educação à população por meio de um moderno sistema de difusão que estava em uso no Brasil e no mundo.

Alves (2010) afirma ainda que outras instituições surgiram nos anos que se seguiram, como o Instituto Rádio Monitor, em 1939, no Estado de São Paulo; o Instituto Universal Brasileiro, com o objetivo de formação em nível médio, em 1941; o Instituto Adventista se lançou na transmissão via Rádio Postal, com o programa 'A voz da profecia', em 1943.

O SENAC - Serviço Nacional de Aprendizagem Comercial - iniciou em 1946 suas atividades e desenvolveu, no Rio de Janeiro e São Paulo, a Universidade no Ar, que em 1950 já atingia 318 localidades e 80 alunos; em 1973, iniciou os cursos por correspondência, seguindo o modelo da Universidade de Wisconsin - USA (ALVES, 2010, p. 3).

Além disso, a Igreja Católica, por meio da Diocese de Natal, no Rio Grande do Norte, em 1959, estreou programas na rádio, dando início ao Movimento de Educação de Base (MEB). O movimento estava preocupado com a alfabetização das classes menos favorecidas, mas foi abandonado devido à repressão política e ao Golpe de 1964.

O projeto intitulado Minerva tinha como objetivo a utilização do rádio para a formação na Educação Básica. Alves (2010) relata que, em São Paulo, foi fundada em 1962, uma escola de origem americana voltada ao campo da eletrônica, denominada Ocidental School, que possuía alunos no Brasil e em Portugal. Em 1967, houve também, a criação do IBAM - Instituto Brasileiro de Administração Municipal, que ofertava cursos na modalidade a distância, voltados ao ensino por correspondência.

De acordo com Alves (2010), no final da década de 1980 e início da década de 1990, período em que a EaD sofreu grande avanço, principalmente, pela informatização e por projetos de difusão da língua estrangeira, o Brasil registrou um grande número de cursos que ofereciam instruções por meio de programas de computadores, vídeos e fitas K-7, como formas de autoaprendizagem.

Posteriormente, um marco histórico para o ensino a distância na história da educação brasileira foi a criação, na década de 1990, do Telecurso 2000 pela Fundação Roberto Marinho, que vinculava programas na emissora Globo e materiais impressos.

Em paralelo ao crescimento da EaD, ratificado pela promulgação da Lei no. 9.394/96, foi criada a Secretaria Especial de Educação a Distância (SEED), por meio do Decreto no 1.917, extinta em 2011. De acordo com Alves (2010), a partir de 1998 há um acentuado crescimento das Instituições de Ensino Superior (IES) que passam a ofertar cursos na modalidade de educação a distância. Além disso, aumentaram também as solicitações de autorização junto ao Ministério de Educação para abertura de cursos nessa modalidade de ensino.

O rápido avanço e expansão da $\operatorname{EaD}$ a partir da promulgação da LDBEN se dá principalmente pela utilização das Novas Tecnologias da Informação e Comunicação (TIC) como via para o processo de ensino e aprendizagem. $\mathrm{Na}$ EaD, a plataforma moodle, por exemplo, torna-se a sala de aula virtual, meio pelo qual professor e aluno interagem, trocam informações, os alunos realizam as suas atividades e assistem as aulas.

Apesar dos avanços e do movimento em prol da EaD, esta modalidade de ensino carece de estudos que a fundamente. A partir desta necessidade o Grupo de Pesquisa Educação a Distância e Tecnologias Educacionais/CNPQ da Universidade Estadual de Maringá (UEM) estuda, entre outros, o livro intitulado "Conceito de Tecnologia" de Álvaro Vieira Pinto, publicado postumamente em 2005, mas que foi escrito pelo autor em 1973. Neste artigo objetivamos 
apresentar, ainda que de forma sucinta, o conceito de tecnologia defendido pelo autor estabelecendo suas relações com a EaD.

\section{METODOLOGIA}

O objetivo desta pesquisa é compreender o conceito de tecnologia defendido por Álvaro Vieira Pinto (2005). Para tanto, realizamos a leitura, interpretação e discussão do volume 1 da obra "Conceito de Tecnologia". Demo $(2000$, p. 20) pontua que a pesquisa de base teórica é aquela que é "dedicada a reconstruir teorias, conceitos, ideias, ideologias, polêmicas, tendo em vista, em termos imediatos, aprimorar fundamentos teóricos". Para o autor, esse tipo de pesquisa é direcionada com o intuito da reconstrução de teorias, referências, explicação da realidade, temas atuais e outras discussões que se fazem pertinentes, não provoca a contribuição social imediata, no entanto, é muito importante pois cria condições para que questões sociais possam ser revisitadas, questionadas e transformadas.

\section{RESULTADOS}

A discussão do conceito de tecnologia realizado por Álvaro Vieira Pinto descreve o homem dentro do processo de hominização, sob duas óticas: a primeira pela capacidade humana de projetar; a segunda, pela formação de um ser social, condição essencial para produzir o que foi projetado. Na perspectiva destes dois conceitos, o autor apresenta o conceito de filosofia da técnica, a qual consiste na arte de sempre fazer algo novo. Diante disso, o autor destaca a importância da técnica como libertadora, ressaltando a necessidade do homem ser o agente do seu ambiente e da sua qualidade de vida.

A fim de que o homem seja promotor de seu ambiente, o autor defende que para o desenvolvimento econômico ocorra em nível global é preciso romper com a dinâmica universal de que a tecnologia é detida por poucos, restando aos países subdesenvolvidos apenas receber as inovações tecnológicas. Passar de país subdesenvolvido para país desenvolvido requer uma mudança em todos os segmentos da sociedade. É preciso que se estabeleça uma relação entre o homem e o mundo, onde este possa ter controle da sua realidade e acesso à recursos avançados. Mais do que isto, é preciso consciência crítica da mudança da realidade, visto o quanto elas são importantes.

O autor critica o uso do termo "era tecnológica", pois este termo é utilizado para expressar apenas os avanços conquistados atualmente, como se não houvesse avanços tecnológicos em todas as etapas do desenvolvimento humano. Ressalta também em seu texto os diferentes níveis de tecnologias e a apropriação inadequada que os países desenvolvidos fazem das riquezas dos países subdesenvolvidos. Neste contexto, o conceito da "era tecnológica" se torna uma expressão de dominação.

Vieira Pinto (2005) destaca também que para vislumbrar essas diferenças é preciso romper com o círculo vicioso, entre países desenvolvidos e países subdesenvolvidos, de falsa totalidade, de que todos podem participar das decisões que são tomadas sobre o futuro dos países. Para o autor, estamos em um momento que não há como recuar ou abrir mão da participação de todos.

É preciso ter consciência de que estamos em um novo estágio, no que se refere a técnica e a sua influência diante da mecanização do trabalho. Em sua perspectiva estamos no estágio do conhecimento e, neste sentido, tudo o que é consumido faz parte da dinâmica e da estrutura econômica e política da sociedade, ou seja, tudo o que é produzido, criado, fabricado, faz parte da expressão da sua realidade e das suas necessidades contextualizada historicamente.

A relação que se estabelece entre homem e máquina, por meio da automatização, da invenção das máquinas reguladoras e das linhas de produção, também se constitui tema de debate para Vieira Pinto (2005) uma vez que o autor questiona se é somente o homem que detém a qualidade de ser pensante, ou esta qualidade também pode ser atribuída a máquina. $O$ autor 
responde ao seu questionamento dizendo que a máquina se justifica socialmente como fruto do desenvolvimento social e do pensamento do homem, reflexo da sua cultura, e, enquanto criação humana, ao mesmo tempo o homem é criador e consumidor da sua criação.

\section{DISCUSSÃO}

Assim como Vieira Pinto (2005) estabelece relação entre o homem e a técnica a fim de que este tenha domínio sobre o seu ambiente e nele faça mudanças, a EaD também busca, da mesma forma, na relação entre homem e tecnologia, levar o sujeito a ter domínio sobre o seu ambiente e nele fazer mudanças, desenvolvendo assim suas habilidades cognitivas por meio da Educação. $A$ EaD surge como uma modalidade de educação que é vista como alternativa ao modelo presencial. Destaca-se pela flexibilidade, realização de trabalho de forma remota, maior autonomia do aluno.

A EaD não se trata de um "modismo tecnológico", pois essa modalidade de ensino existe há mais de dois séculos, no entanto a sua expansão ocorreu somente nas três últimas décadas. Nesse sentido, as TIC propiciaram, de forma gradativa, uma maior acessibilidade e flexibilidade à cultura, à educação e à formação profissional, contribuindo assim para a "criação de sistemas educacionais no futuro" (OLIVEIRA, 2003, p. 40).

A EaD é muito mais do que utilizar as tecnologias em sala de aula, pois envolve uma visão mais ampla. Nela há interatividade, que seria a relação biunívoca entre professor e aluno, resultando em aquisição do conhecimento (NISKIER, 1999). Nesse contexto, ressaltamos ainda que a educação a distância deverá capacitar para: racionalização e resolução de problemas em longo prazo; refrear as incertezas; separar os objetivos possíveis dos menos prováveis; antecipar os possíveis padrões de educação que podem ser implantados; democratizar o acesso a educação do maior número de pessoas; permitir a flexibilidade; enriquecer a experiência individual; promover a habilidade de observação; propiciar a utilização de diversos recursos de multimídia; promover a autonomia do aluno; educar para a construção do conhecimento (NISKIER, 1999).

Belloni $(2001$, p. 3) pontua que a EaD está cada vez mais presente no contexto educacional da sociedade contemporânea, pois consiste em "uma modalidade de educação extremamente adequada e desejável para atender às novas demandas educacionais decorrentes das mudanças na nova ordem econômica mundial". Para esta autora, a EaD caminha para se tornar um elemento regulador dos sistemas de ensino, imprescindível não somente para atender à demanda de grupos específicos, mas também para ganhar destaque no ensino superior e na formação continuada.

A autora ainda enfatiza que a EaD se gere em um contexto de novos sujeitos, oriundo das mudanças ocorridas nas relações entre cidadania, aprendizagem e trabalho. Nesse cenário, estes novos sujeitos deverão apresentar alguns saberes estratégicos para a vida cidadã em um contexto democrático como trabalhar em grupo, localizar informações e utilizá-las com criatividade, serem críticos quanto aos meios de comunicação, compreenderem sua forma e saberem atuar nele além de dominar as linguagens.

Nesse sentido, diante da EaD e da complexidade com que ela se apresenta, ainda encontramos os que pensam que fazer um curso nessa modalidade é reproduzir os conteúdos trabalhados presencialmente de forma interessante, conforme aponta Ramal (2003). Acreditamos que ensinar e aprender por meio da EaD não seja tão simples, pois exige que o material seja bem selecionado e planejado, com linguagem dialógica, a fim de que envolva os estudantes. Do aluno, a EaD exige disciplina de estudo, autonomia e pró-atividade, uma vez que há uma distância transacional entre aluno e professor.

As TIC e a EaD são uma realidade possível de transformar a vida de milhões de brasileiros. Enquanto tecnologia desenvolvida pelo e para o homem é necessário que ela não fique restrita a usuários pagantes desse tipo de tecnologia. É preciso que ações políticas, econômicas e sociais, que vão desde ofertar uma internet de qualidade gratuitamente a todos até o letramento digital, seja uma realidade. 


\section{CONCLUSÃO}

Estudar o conceito de tecnologia estabelecido por Vieira Pinto (2005) nunca foi tão atual se vislumbrarmos a atual conjuntura da EaD. Com a ascensão das TIC, se configura a Educação a Distância no modelo que a conhecemos atualmente, visando atender ao homem de uma sociedade imediatista, individualista e que se vê imerso aos processos de produção do trabalho, gerando assim a necessidade da oferta de uma educação flexível que se adapte a rotina do homem contemporâneo.

Por outro lado, é preciso refletir sobre como a EaD pode, por meio da utilização das TIC, envolver mais pessoas na busca pelo conhecimento. As novas tecnologias devem ser disponibilizadas a todos e não se tornar apenas uma forma atual de alienação e estratificação social e cultural.

\section{REFERÊNCIAS}

ALVES, J. R. M. Educação a distância e as novas tecnologias de Informação e Aprendizagem. Disponível em:

<http://www.educadores.diaadia.pr.gov.br/arquivos/File/2010/artigos_teses/EAD/EDUCADIST.PD F>. Acesso em: 15 de ago. 2016.

BELLONI, M. L. Educação a Distância. Campinas, SP: Autores Associados, 2001.

BRASIL. Ministério da Educação e da Cultura. Lei de Diretrizes e Bases da Educação: Lei no 9.394/96 - 24 de dez. 1996. Estabelece as diretrizes e bases da educação nacional. Brasília, 1996. Disponível em:<http://www.planalto.gov.br/ccivil_03/leis//9394.htm>. Acesso em: 15 de ago. 2016.

DEMO, P. Conhecer \& aprender: sabedoria dos limites e desafios. Porto Alegre: Artmed, 2000.

NISKIER, A. Educação à Distância: a tecnologia da esperança. São Paulo: Edições Loyola, 1999.

OLIVEIRA, E. G. Educação a Distância na Transição Paradigmática. Campinas, SP: Papirus, 2003 (Coleção Magistério: Formação e Trabalho Pedagógico).

PINTO, Á. V. O conceito de tecnologia. vol. 1. Rio de Janeiro: Contraponto, 2005.

RAMAL, A. C. Educação a Distância: entre mitos e desafios. In: ALVES, Lynn; NOVA, Cristiane. Educação a Distância: uma nova concepção de aprendizagem e interatividade. São Paulo: Futura, 2003. p. 43-50. 